\title{
Prisoners' attitudes towards cigarette smoking and smoking cessation: a questionnaire study in Poland Alicja Sieminska*1, Ewa Jassem ${ }^{1}$ and Krzysztof Konopa ${ }^{2}$
}

\author{
Address: ${ }^{1}$ Department of Pneumonology and Allergology, Medical University of Gdansk, Debinki 7, 80-952 Gdansk, Poland and ${ }^{2}$ Department of \\ Oncology and Radiotherapy, Medical University of Gdansk, Debinki 7, 80-952 Gdansk, Poland \\ Email: Alicja Sieminska* - kulikala@interia.pl; Ewa Jassem - ejassem@amg.gda.pl; Krzysztof Konopa - konopa@amg.gda.pl \\ * Corresponding author
}

Published: 07 July 2006

BMC Public Health 2006, 6:181 doi:10.1 |86/147|-2458-6-181
Received: 13 February 2006

Accepted: 07 July 2006

This article is available from: http://www.biomedcentral.com/I47I-2458/6/18I

(c) 2006 Sieminska et al; licensee BioMed Central Ltd.

This is an Open Access article distributed under the terms of the Creative Commons Attribution License (http://creativecommons.org/licenses/by/2.0), which permits unrestricted use, distribution, and reproduction in any medium, provided the original work is properly cited.

\begin{abstract}
Background: In the last decade Poland has successfully carried out effective anti-tobacco campaigns and introduced tobacco control legislation. This comprehensive strategy has focused on the general population and has led to a considerable decrease in tobacco consumption. Prisoners constitute a relatively small part of the entire Polish population and smoking habits in this group have been given little attention. The aim of the study was to assess the prevalence of cigarette smoking in Polish male prisoners, factors determining smoking in this group, prisoners' attitudes towards smoking cessation, and to evaluate prisoners' perception of different anti-tobacco measures.

Methods: An anonymous questionnaire including personal, demographic and smoking data was distributed among 944 male inmates. Of these, 907 men aged between 17 and 62 years (mean 32.3 years) met the inclusion criteria of the study. For the comparison of proportions, a chi-square test was used with continuity correction whenever appropriate.

Results: In the entire group, $81 \%$ of the subjects were smokers, $12 \%$ - ex-smokers, and $7 \%$ - never smokers. Current smokers had significantly lower education level than non-smokers $(p<0.000 \mathrm{I})$ and ever-smokers more frequently abused other psychoactive substances than never smokers ( $P$ $<0.000 \mathrm{I})$. Stress was reported as an important factor in prompting smoking $(77 \%)$. Forty-nine percent of daily smokers were aware of the adverse health consequences of smoking. The majority of smokers (75\%) had attempted to quit smoking in the past. Forty percent of smoking prisoners considered an award for abstaining from cigarettes as the best means to limit the prevalence of smoking in prisons.

Conclusion: The prevalence of cigarette smoking among Polish prisoners is high. However, a majority of smokers attempt to quit, and they should be encouraged and supported. Efforts to reduce cigarette smoking in prisons need to take into consideration the specific factors influencing smoking habits in prisons.
\end{abstract}

\section{Background}

By the late 1980 's only $10 \%$ of adult Polish men had never smoked placing Poland among those countries with the highest tobacco consumption in the world $[1,2]$. After 
introducing democratic changes and the market economy, Poland has become the target of the international tobacco industry being considered one of the best potential outlets. The tobacco industry quickly developed very aggressive tobacco advertising and promotions. Poland, however, successfully attempted to create a comprehensive tobacco control strategy, mainly through the introduction of new legislative measures [1]. The first antitobacco bill introduced in 1996, requested the biggest health warnings labels in Europe, and three years later all advertising in newspapers and on billboards were banned. This was accompanied by continuous increases in tobacco taxation with part of the taxes devoted to funding prevention efforts. Other anti-smoking measures included comprehensive information about health consequences of tobacco use, policies designed to prevent smoking in public places, workplaces, and other facilities, withdrawal of cigarette vending machines, forbidding the sale of loose cigarettes and sales to people under the age of 18 .

All these measures have led to a gradual and steady decrease in tobacco consumption in both sexes and across age bands, except women aged 40-60 [3-5]. In the general population of adult men (mostly well-off and educated), the rate of $52 \%$ of daily smokers in 1990 decreased to $39 \%$ in 2002, and the rate of ex-smokers in the years $1990-1993$ increased from $14 \%$ to $20 \%$ in the years 1997-2000. In the same period the prevalence of daily smoking in the general population of adult women dropped slightly from $26 \%$ to $24 \%[2,5]$. However, these positive changes have not occurred in adults with a lower socio-economic status. The rate of daily smokers in this population is still higher compared to the general population: 53\% among men and 30\% among women [5].

Educationally and socio-economically disadvantaged groups are typically characterized by an increased criminality [6]. At present 80.000 people in Poland $(2.7 \%$ of the general adult population) are incarcerated in the custodies or prisons $[6,7]$. The issue of tobacco smoking in this population has been neglected by public health sector, and health and economic benefits of smoking cessation in this community have not been estimated. Correctional facilities have not been taken into consideration in the national anti-tobacco strategies either. Very little attention has also been given to help prisoners stop smoking, although incarceration might be an opportunity to promote smoking cessation. On the other hand, prisoners' attitudes towards smoking cessation, their motivation to quit and awareness of a harmful smoking impact on health have not been investigated. Consequentially, it is not known whether prisoners are interested in participating in a smoking cessation or reduction program. Tobacco smoking in the correctional population has also been given little attention in other countries [8-13]. For example, in Australia, where tobacco control in the general community is of high priority, prison facilities have not been a target area for the state tobacco strategies [13]. In the USA, except for the implementation of some restrictions on smoking in some prisons, during the last 25 years no smoking cessation interventions in correctional systems have been reported in literature, whilst at the same time a number of anti-smoking interventions in other communities have been implemented [8].

The lack of data on tobacco smoking in Polish prisons prompted us to investigate this issue. We aimed to investigate the prevalence of smoking among male prisoners and their attitudes towards cigarette smoking and smoking cessation, as well as to establish their opinion on different anti-smoking measures. It could help to work out the most effective smoking cessation programmes addressed to this specific community.

\section{Methods}

We used the data collected in the survey of Central Headquarters of Penitentiary Service (CHPS). Because the survey was conducted for internal programme development, ethical approval was not obtained prior to data collection. In the questionnaire form the respondents were informed about the aim of the study and possibility of "release of given information", as well as about the fact that participation in the questionnaire survey was totally voluntary and anonymous. A respondent's consent was taken into account while filling the questionnaire. Before analysing the data, the authors received permission from CHPS to use it in the present study.

The study sample was randomly selected among men incarcerated in prisons and jails of the Gdansk, Lublin and Lodz Penitentiary Districts in Poland. An anonymous voluntary questionnaire on cigarette smoking was distributed among 944 men. The questions referred to age, education, imprisonment status, smoking status, substance abuse, smoking initiation, the number of cigarettes smoked per day and changes in smoking habits in prison, factors enhancing smoking, the awareness of smoking consequences on health, the previous attempts to quit smoking, reasons to quit, and the causes of relapses [see Additional file 1].

The level of education was recorded as primary, vocational, secondary and university. According to an imprisonment status respondents were classified as provisionally detained, first sentenced and recidivist. To the first category of inmates, subjects held in pre-adjudication detention were classified (in the Polish legal system, the cumulative term of the pre-adjudication detention until the detainee has been convicted - cannot exceed two 
years). Smokers (daily and occasional), ex-smokers and never-smokers were defined according to the WHO criteria: 1) a smoker was someone who, at the time of the survey, smoked any tobacco product either daily (daily smoker) or occasionally (occasional smoker), 2) exsmoker was someone, who formerly had smoked daily, but, at the time of the survey, did not smoke at all, 3) never-smoker was someone, who either had never smoked at all or had never been daily smoker and had smoked less than 100 cigarettes (or the equivalent amount of tobacco) in his lifetime [14]. The assessment of substance abuse was carried out on the base of self-perception of substance use: "If you consider yourself as an abuser of any of the following substances, check one or more of the given patterns of your substance abusing: drinking excessive amount of spirits daily, drinking spirits once a week excessively, drinking too much wine or beer daily, tranquillisers, analgesics or other drugs abuse, narcotics, e.g., heroin, marijuana, cocaine, amphetamine abuse, incidental narcotic using and no substance abuse. According to the chosen pattern of alcohol drinking, taking into account the frequency, amount and type of alcohol beverages consuming, alcohol abusers were further recorded as: very excessive drinkers (daily spirits drinkers), excessive drinkers (drinking spirits excessively once a week) and mild drinkers (wine or beer daily drinkers).

The prisoners were also asked about their opinion on the given strategies for smoking cessation in prison. The question was: "How effective, in your opinion, each antismoking strategy would be: individual therapeutic meetings, group therapeutic meetings, system of awards for smokers abstaining from cigarettes (e.g. permission for additional visits or walks), anti-tobacco audio-visual measures - broadcasts or posters, nicotine replacement therapy, pharmacological agents (e.g., antidepressants)? Each strategy may be determined as not efficacious, low efficacious, efficacious or very efficacious".

\section{Statistical analysis}

For the comparison of proportions, a chi-square test was used with continuity correction whenever appropriate. All reported values were two-sided. Statistical analysis was performed using the software package Statistica 6.0.

\section{Results}

The response rate was $100 \%$. However, $4 \%$ of questionnaires were not evaluated since they did not meet the criteria of the self-reported questionnaire. Finally, 907 men aged between 17 and 62 years (mean age 32.3 years) were included in the study. The distribution of the study population according to smoking status and selected characteristics is shown in Table 1.
A total of 841 respondents (93\%) had a cigarette smoking history, including $736(81 \%)$ current and $105(12 \%)$ former smokers. The majority of ever-smokers (96\%) reported smoking initiation before imprisonment. Only $4 \%$ of smokers started smoking in prison. Among smokers, $696(95 \%)$ were daily and $40(5 \%)$ occasional smokers. The distribution of daily cigarette smokers, according to selected characteristics of a smoking habit is shown in Table 2.

\section{Smokers awareness of the negative impact of smoking on health}

Among prisoners with secondary and university education, $28 \%$ of smokers were aware of the negative impact of cigarette smoking on health, whereas among those with basic education - only 19\%; ( $\mathrm{p}=0.033)$. The knowledge of negative effect of smoking on health was significantly more frequent in former smokers than in current daily smokers ( $63 \%$ and $49 \%$ respectively; $\mathrm{p}=0.02)$.

\section{Factors influencing cigarette smoking and smoking cessation}

The majority of smokers (75\%) reported a stronger need to smoke while imprisoned than free, enhanced by a number of specific "prison" factors. The most frequent factors prompting cigarette smoking in prison are shown in Table 3. An equal proportion of smokers (75\%) reported smoking cessation attempts ever in the past, both while being free $(46 \%)$ and imprisoned $(54 \%)$. The remaining $25 \%$ of smokers had never tried to stop smoking. The main reasons for quitting cigarettes are shown in Table 3.

The survey on awareness of smoking consequences on health demonstrated that quitters were more frequently aware of cigarette harmfulness than never-quitters, 55\% vs. $33 \%$ respectively $(\mathrm{p}<0.001)$.

Smokers who had never tried to quit cigarettes in the past were more likely to smoke over 20 cigarettes per day in comparison to those who attempted to stop smoking ( $26 \%$ and $17 \%$, respectively; $\mathrm{p}=0.0095)$. There were no significant differences according to the level of education $(\mathrm{p}=0.139)$ and the imprisonment status between quitters and never-quitters $(\mathrm{p}=0.19)$. Both groups did not differ in the prevalence of other substance abuse, except for very excessive and excessive spirit abusing. These patterns of alcohol abuse were more frequent among never-quitters than among quitters $(36 \%$ and $28 \%$, respectively; $\mathrm{p}=$ $0.04)$.

Over a half (52\%) of quitters had attempted to stop smoking up to five times, and the remaining smokers had tried more than five times. The majority (64\%) of former smokers (those who had successfully stopped smoking) 
Table I: Distribution of the study population according to smoking status and selected characteristics

\begin{tabular}{|c|c|c|c|c|c|c|c|c|}
\hline \multirow[t]{3}{*}{ Characteristics } & \multicolumn{2}{|c|}{ Total } & \multicolumn{6}{|c|}{ Smoking status } \\
\hline & \multirow[b]{2}{*}{ No. } & \multirow[b]{2}{*}{$(\%)$} & \multicolumn{2}{|c|}{ Smokers } & \multicolumn{2}{|c|}{ Ex-smokers } & \multicolumn{2}{|c|}{ Never-smokers } \\
\hline & & & No. & $\%$ & No. & $\%$ & No. & $\%$ \\
\hline Total number of subjects & 907 & $(100)$ & 736 & 81 & 105 & 12 & 66 & 7 \\
\hline \multicolumn{9}{|l|}{ Age } \\
\hline$\leq 20$ & 85 & (9) & 74 & 87 & 4 & 5 & 7 & 8 \\
\hline $21-30$ & 372 & $(4 I)$ & 296 & 79 & 51 & 14 & 25 & 70 \\
\hline $31-40$ & 253 & (28) & 203 & 80 & 28 & 11 & 22 & 9 \\
\hline $41-50$ & 156 & (17) & 132 & 85 & 16 & 10 & 8 & 5 \\
\hline$>50$ & 41 & $(5)$ & 31 & 75 & 6 & 15 & 4 & 10 \\
\hline \multicolumn{9}{|l|}{ Imprisonment status* } \\
\hline Provisionally detained & 319 & (35) & 238 & 75 & 37 & II & 44 & 14 \\
\hline First sentenced & 227 & (25) & 193 & 85 & 21 & 9 & 13 & 6 \\
\hline Recidivists & 351 & (39) & 297 & 85 & 45 & 13 & 9 & 2 \\
\hline Missing data & 10 & $(\mathrm{I})$ & 8 & 80 & 2 & 20 & 0 & 0 \\
\hline \multicolumn{9}{|l|}{ Education $* *$} \\
\hline Elementary or vocational school & 648 & (7I) & 544 & 84 & 65 & 10 & 39 & 6 \\
\hline Secondary/university & 226 & (25) & 164 & 72 & 38 & 17 & 24 & II \\
\hline Missing data & 33 & $(4)$ & 28 & 85 & 2 & 6 & 3 & 9 \\
\hline $\begin{array}{l}\text { Alcohol and/or illicit drug } \\
\text { abuse } * * *\end{array}$ & $500^{\dagger}$ & $(55)$ & 434 & 87 & 46 & 9 & 20 & 4 \\
\hline Very excessive drinkers & 122 & $(13)$ & 107 & 88 & 10 & 8 & 5 & 4 \\
\hline Excessive drinkers & 130 & (14) & 112 & 86 & 13 & 10 & 5 & 4 \\
\hline Mild drinkers & $|5|$ & (17) & 135 & 89 & 9 & 6 & 7 & 5 \\
\hline Drug abusers & 95 & (10) & 76 & 80 & 16 & 17 & 3 & 3 \\
\hline Drug incidentally users & 94 & (10) & 80 & 85 & 8 & 9 & 6 & 6 \\
\hline No substance abuse reported & 362 & $(40)$ & 261 & 72 & 55 & 15 & 46 & 13 \\
\hline Missing data & 45 & $(5)$ & 41 & 91 & 4 & 9 & 0 & 0 \\
\hline
\end{tabular}

$* p=0.0002$ comparing the rates of smokers and non smokers (combined ex- and never smokers) among subjects provisionally detained vs. others (first sentenced and recidivists)

** $p<0.0001$ comparing the rates of smokers and non-smokers among subjects with secondary/university education vs. others (combined subjects with primary/vocational education and missing data).

*** $p<0.0001$ comparing the rates of ever-smokers (combined current and former smokers) and never smokers among alcohol and/or illicit drug abusers vs. no substance abusers.

t The number of 500 subjects reporting alcohol and/or illicit drug abusing does not reflect a total of the listed subcategories of abusers, because they are not exclusive.

achieved it in 1 to 3 attempts. Thirty-one per cent of subjects stopped smoking in the first attempt. Only nineteen smokers successfully stopped smoking during their stay in prison, composing $18 \%$ of former smokers. That number represented $2 \%$ of the surveyed ever-smokers.

The most frequent cause (67\%) of failure in cigarette quitting was stress, either as a single cause, or in combination with other causes. Other factors included: alcohol drinking $(25 \%)$, boredom $(10 \%)$, depressed mood $(8 \%)$, joy $(5 \%)$ and yielding to one's persuasion $(4 \%)$.

\section{Prisoners opinion on anti-smoking strategies}

Forty per cent of smokers and ex-smokers considered the system of awards for smokers abstaining from cigarettes (e.g. permission to have additional visits or walks) the best measure to limit the prevalence of smoking among prisoners. Nicotine replacement therapy, individual ther- apeutic meetings, pharmacological agents (e.g., antidepressants), group therapeutic meetings and anti-tobacco audio-visual measures - broadcasts or posters - were assessed as very efficacious by $24 \%, 21 \%, 21 \%, 19 \%, 5 \%$ and $4 \%$ of smokers respectively. The estimation of the effectiveness of antismoking measures by prisoners was not related to the level of their education or to alcohol or substance abuse except for narcotics abusers, who more frequently considered an award system as the most effective $(\mathrm{p}=0.02)$.

\section{Discussion}

The community of prisoners differs from other social groups in terms of psychosocial factors, the level of education, alcohol and substance abuse, attitudes towards health, and lifestyle. All these factors account for the generally higher prevalence of tobacco smoking among prisoners, in comparison with a general population [8-11]. In 
Table 2: Distribution of daily cigarette smokers, according to selected characteristics of the smoking habit

\begin{tabular}{|c|c|c|c|c|}
\hline \multirow[t]{2}{*}{ Characteristic } & \multicolumn{2}{|c|}{ Current smokers } & \multicolumn{2}{|c|}{ Former smokers } \\
\hline & No. & $\%$ & No. & $\%$ \\
\hline Total No. of daily cigarette smokers & 696 & 100 & 27 & 100 \\
\hline \multicolumn{5}{|l|}{ Age of smoking initiation: } \\
\hline$\leq 10$ & 55 & 8 & 0 & 0 \\
\hline $11-13$ & 95 & 14 & 1 & 4 \\
\hline $14-17$ & 329 & 47 & 6 & 22 \\
\hline $18-20$ & 153 & 22 & 5 & 18 \\
\hline $21-25$ & 42 & 6 & 2 & 7 \\
\hline$>25$ & 16 & 2 & 5 & 18 \\
\hline Missing data & 6 & 1 & 8 & 30 \\
\hline \multicolumn{5}{|l|}{ No. of cigarettes smoked daily: } \\
\hline $\mathrm{I}-5$ & 12 & 2 & 6 & 22 \\
\hline $6-10$ & 128 & 18 & 6 & 22 \\
\hline $11-15$ & 116 & 17 & 4 & 15 \\
\hline $16-20$ & 293 & 42 & 3 & 1 \\
\hline $21-40$ & 126 & 18 & 1 & 4 \\
\hline$>40$ & 15 & 2 & 0 & 0 \\
\hline Missing data & 6 & 1 & 7 & 26 \\
\hline \multicolumn{5}{|l|}{ No. of pack/years: } \\
\hline$\leq 10$ & 324 & 46 & 18 & 67 \\
\hline $1 \mathrm{I}-20$ & 179 & 26 & 1 & 4 \\
\hline $21-30$ & 90 & 13 & I & 4 \\
\hline $31-40$ & 47 & 7 & 0 & 0 \\
\hline $4 I-50$ & 21 & 3 & 0 & 0 \\
\hline $51-70$ & 18 & 3 & 0 & 0 \\
\hline$>70$ & 6 & 1 & 0 & 0 \\
\hline Missing data & 11 & 2 & 7 & 26 \\
\hline \multicolumn{5}{|l|}{ Smoking the first cigarette: } \\
\hline Within 30 min. after awakening & 553 & 79 & 1 & 4 \\
\hline Later & $|3|$ & 19 & 4 & 15 \\
\hline Missing data & 12 & 2 & 22 & 81 \\
\hline \multicolumn{5}{|l|}{ Smoking a greater No. of cigarettes: } \\
\hline In the morning & 310 & 44 & 3 & 11 \\
\hline In the afternoon & 374 & 54 & 2 & 7 \\
\hline Missing data & 12 & 2 & 22 & 81 \\
\hline \multicolumn{5}{|l|}{ Changes in smoking habit in prison: } \\
\hline Smoking less cig/d. than at liberty & 202 & 29 & - & - \\
\hline Smoking more cig/d. & 231 & 33 & - & - \\
\hline Smoking the same No. of cig/d. & 240 & 35 & - & - \\
\hline Missing data & 23 & 3 & - & - \\
\hline \multicolumn{5}{|l|}{ Awareness of smoking negative impact on health: } \\
\hline Aware smokers* & 345 & 49 & 6 & 22 \\
\hline Smokers not contemplating whether smoking is harmful & 227 & 33 & 3 & 11 \\
\hline Smokers denying health impacts of smoking** & 103 & 15 & 0 & 0 \\
\hline Missing data & 21 & 3 & 18 & 67 \\
\hline
\end{tabular}

*smokers convinced about smoking harmfulness for health; **smokers convinced that smoking did not affect health in any way

Poland tobacco smoking in the correctional population has not been investigated so far, making this the first study on the subject.

In a randomly selected study group of male prisoners, accounting for nearly $1.2 \%$ of all Polish imprisoned males [6], we found extremely high rate of smokers. The data on the prevalence of smoking among female inmates remain still unavailable. Australian and American studies reported high rates of smokers among female correctional populations [8-10]. Among Queensland and Mississipi female prisoners the rates of smokers were $83 \%$ and $74 \%$, respectively $[8,9]$. In American survey among female arrestees, the prevalence of smoking was also high, with the rate of $91 \%$ and $42 \%$ of daily smokers in New York and Los Angeles samples, respectively [10]. In all cases the rates of smoking were higher than in a general population. Similarly, in another Australian study, regarding 
Table 3: Most frequent factors promoting cigarette smoking during incarceration and smoking cessation (both in prison and at liberty)

\begin{tabular}{|c|c|c|}
\hline Factors & No. of subjects & $\%+$ \\
\hline \multicolumn{3}{|l|}{ Factors promoting cigarette smoking in prison } \\
\hline Missing family and close friends & 435 & 66 \\
\hline The lack of freedom & 381 & 57 \\
\hline Boredom & 295 & 44 \\
\hline Anxiety about affairs to deal with at liberty & 232 & 35 \\
\hline The lack of sex & 206 & 31 \\
\hline Anxiety about the case and sentence & 156 & 23 \\
\hline Qualms about the crime committed & 116 & 17 \\
\hline Bad relations with the penitentiary staff & 113 & 17 \\
\hline Bad relations with other prisoners & 86 & 13 \\
\hline The lack of alcohol & 70 & 10 \\
\hline The lack of narcotics & 37 & 6 \\
\hline Other factors & 21 & 3 \\
\hline Missing data & 72 & 11 \\
\hline \multicolumn{3}{|l|}{ Factors promoting smoking cessation } \\
\hline Anxiety about health & 231 & 46 \\
\hline The fight with own weakness & 142 & 28 \\
\hline The will to save some money & 120 & 24 \\
\hline Limited access to cigarettes & 109 & 21 \\
\hline Somebody's instigation & 37 & 7 \\
\hline The will to gain an authority & 10 & 2 \\
\hline Other (e.g., the bet with somebody, tobacco related disease in the family, physical or body-building activities) & 32 & 6 \\
\hline Missing data & 240 & 32 \\
\hline
\end{tabular}

† The percentages were estimated after excluding 72 and 240 smokers who had not replied to the questions regarding factors promoting cigarette smoking in prison and smoking cessation (both in prison and at liberty), respectively.

both female and male correctional population, the rate of $79 \%$ of smokers was reported (three times more than that of a general population) [11].

In this survey, smoking habits were significantly more frequent among convicts (first sentenced and recidivists) than among provisional detainees. Moreover, smokers were more likely to be less educated, and this correlation was also reflected in other studies on general community populations $[15,16]$ and Australian survey on female prisoners [9].

Almost all smokers in our sample started to smoke before imprisonment, and, in the light of three of Fagerström's criteria, the majority of them seemed to be strongly addicted to nicotine at the time of the survey [17]. The rates of smokers smoking 11-20 cigarettes daily and smokers having their first cigarette within 30 minutes after awakening were $59 \%$ and $79 \%$, respectively.

It is considered, that people inclined to criminal and antisocial behaviours are likely to be predisposed to other forms of risky behaviours including tobacco and other substances abuse, mainly alcohol [18]. Moreover, alcohol drinking proved to be the strongest factor prompting relapses following smoking cessation [19], and ex-smok- ers seemed less likely to be alcohol abusers in comparison with current smokers [20]. Our study showed that among prisoners who defined themselves as alcohol and/or illicit drug abusers, almost $90 \%$ were current smokers. Alcohol was also an important factor prompting relapses in quitting. Smokers who had successfully quit smoking and never smokers significantly less frequently reported alcohol and/or other substances abuse than current smokers.

The analysis of factors that provoke smoking in our sample demonstrated the importance of the stress factor. On the other hand, in spite of specific stress resulting from imprisonment, the majority of smokers attempted to stop smoking under prison circumstances, but only $2 \%$ stopped smoking successfully while imprisoned. Surprisingly, the most important trigger to quit smoking was anxiety about health; reported by $46 \%$ of "ever-quitters". Although the awareness of harmfulness to health caused by smoking is generally not satisfactory in Polish correctional population, the commonness of this motivation to quit smoking habits could be in part explained with the Polish anti-tobacco legislation, which specifies that onethird of a pack of cigarette must be covered with warning labels. 
The rate of never-quitters in our sample did not differ from that in other correctional populations, and represented nearly one-fourth of smokers $[8,21]$. However, the prevailing proportion of smokers had previously attempted to stop smoking at least one time, but unfortunately, most attempts to quit were unsuccessful. The rate of $12 \%$ of former smokers, namely subjects who quitted successfully, was relatively low in our sample. It is noteworthy, that every third successful quitter stopped smoking in the first attempt. The high rate of relapses during smoking cessation, mainly within 6 months, is common both in correctional and general populations $[8,22]$. It was previously demonstrated, that usually, people who cannot successfully quit smoking are particularly addicted to nicotine, and one of the most important factors determining relapses is alcohol use $[19,22]$. For that reason the community of prisoners, a substantial part of which consists of smokers usually abusing alcohol and strongly addicted to nicotine, is typically unsuccessful in quitting.

Quite a high proportion of quitters reflect a high willingness to stop smoking and indicate a great need for smoking cessation programmes addressed to them. On the other hand, the relatively high rate of never quitters in our study indicate that some policies should be adopted to improve smokers' information on tobacco consequences for health, and some counselling intervention added to prisons. The American survey conducted in Mississipi female prisons showed the high motivation to quit among current smokers, and the rate of quitters was $60 \%$ [8]. Almost two-thirds of smokers were interested in participating in a smoking cessation programme offered by the prison. In Poland, there are no cessation programmes addressed to prisoners and support offered to them is limited to an incidental advice by a physician examining newly admitted inmates. Thus, it should be of particular importance to add a minimal anti-smoking intervention to medical services in prison. A brief physician advice resulting in increasing quit rates up to $10 \%[23]$ seems an attractive strategy. To be effective, however, the medical staff should regularly attend smoking cessation workshops, which are, unfortunately, not organized in Poland because of the lack of funds.

Psychological studies indicate that smokers who successfully quit smoking were more frequently controlled by their intrinsic rather than extrinsic motives (e.g., the will to receive a reward) $[24,25]$. Smokers prompted by their intrinsic will to quit smoking were twice as frequently successful as smokers who were promised to receive a reward [25]. However, smoking prisoners in our study considered an award system the most efficacious method of cigarette quitting under prison circumstances, where they are deprived of the majority of usual pleasures accessible to free people. Probably, an award such as additional walk- ing, physical training or meetings, including so-called intimate meetings with sexual partners, could be a strong motivational factor to quit or maintain the abstinence in the prison circumstances. This simple intervention encouraging smokers to stop smoking seems possible to be implemented in Polish prisons because of its low costs and high acceptance of smoking prisoners.

As far as the time for having a cigarette is concerned, prisoners in our sample generally smoked more cigarettes in the afternoon and in the evening than during the earlier hours of the day, which is not specific for strongly addicted smokers [17]. It is probably due to the typical Polish prison schedule - most daily activities like work, walking, physical training and meals are finished by four p.m. - making smoking cigarettes one of only very few available activities in the late hours. Thus, it may indirectly confirm the role of boredom as a factor increasing smoking in the second half of a day. Indeed, in our study prisoners reported boredom as an important trigger for smoking. The lack of activities results from many problems affecting Polish penitentiary system. First of all, prisons are over-crowded and since the year 2000 the number of prisoners exceeds the number of available places in prisons by ten thousands $[6,26]$. Besides, only $30 \%$ of prison cells have sufficient light to read and in the majority of prisons there are no community centres, often not even chapels $[6,26]$. The conditions to practise sport or any physical exercises in Polish penitentiary units are unsatisfactory, with few sports or exercise facilities $[6,27]$. As a result, the conditions are conducive to maintaining cigarette smoking, and potential efforts to reduce the demand for tobacco among prisoners may be less effective. Therefore, some regulations on smoking policy ban have been adopted in Poland to reduce the supply of cigarettes, as well as protect non-smokers against tobacco smoke. First of all, inmates sent to a Polish prison should be classified according to the smoking status, which allows to place non-smokers in smoke-free accommodation. Indoor smoking in Polish prisons is permitted only in individual cells and during meetings with visitors, and outdoor smoking - in walking yards. Smoking is banned during work and in all areas where non-smokers could be involuntary exposed to tobacco smoke, for instance community centres, chapels, gymnasium or hospital wards. However, the implementation of this policy has not been consistent. Prisoners who do not smoke are quite frequently accommodated with smoking people without any opportunity for non-smoking housing assignments. Inmates have opportunities to get cigarettes from the commissary or receive cigarettes in the parcels from friends or family members. The restrictive tobacco policies have not been effectively enforced in another countries either, including high income countries [28]. Experiences of these countries allow us to assume that total prohibi- 
tion in Polish prisons would be difficult to enforce, due to several factors, including substantial costs and inmates' opposition to ban smoking in their cells.

The spectrum of potential tobacco policy options for prisoners is quite wide, although there are some difficulties in introducing them into this community [13]. The effectiveness of different anti-smoking interventions in a prison context has not yet been estimated in Poland. In our study, some forms of unstructured smoking cessation programmes like for instance provision of self-help materials or availability of NRT for sale to inmates, were perceived by smokers as low efficacious. Substitution of tobacco given to inmates at reception with NRT could be considered potentially effective, but at present still impossible to enforce in Polish prisons, mainly for economic reasons. There are also no structured quit programmes in Polish prisons, which normally consist of behavioural and pharmacological components and therefore are more costconsuming.

Our findings highlight the crucial need for cessation programmes targeted to prisoners. Efforts to reduce cigarette smoking in prisons need to tackle both group and individual factors, and anti-tobacco programmes should be addressed to all aspects of smoking habits, including behavioural, psychological and biological processes governing addiction to nicotine. These programmes should be also adjusted to Poland's economic opportunities.

\section{Conclusion}

Our findings suggest several implications for policy relevance. First, they indicate that prevalence of cigarette smoking among prisoners is high, particularly among the lower educated and substance abusing subjects. Secondly, the awareness of health consequences of smoking is strikingly low among prisoners, which calls for educational programmes adjusted to this community. Thirdly, the majority of smokers, mainly the better educated, attempt to quit smoking for many reasons. In the opinion of prisoners, the best measure to limit smoking in prisons is a system of awarding smokers for abstaining from smoking cigarettes. Finally, efforts to reduce cigarette smoking in prisons need to take into consideration the specific factors influencing smoking habits in prisons.

\section{Competing interests}

The author(s) declare that they have no competing interest.

\section{Authors' contributions}

AS conceived the study, participated in its design and coordination and drafted the manuscript. EJ participated in the design, coordination, and supervision of the study, and helped to draft the manuscript. KK performed the sta- tistical analysis. All authors read and approved the final manuscript.

\section{Additional material}

\section{Additional File 1}

Provides detailed questions included in the questionnaire Click here for file

[http://www.biomedcentral.com/content/supplementary/14712458-6-181-S1.doc]

\section{Acknowledgements}

The authors would like to thank Dr. D. Odya from Gdansk District Inspectorate of Penitentiary Service, and Dr. G. Sobierajska from Ambulatory of Lodz Penitentiary for their assistance in collecting data, and Prof. J. Jassem from Oncology and Radiotherapy Department of Medical University of Gdansk for reviewing the article and his valuable remarks.

\section{References}

I. Neroth P: Stubbing out Communist habit. Lancet 2005, 366:109-110.

2. Zatonski WA: Tobacco smoking in Central European countries: Poland. In Tobacco Science, Policy and Public Health Edited by: Boyle P, Gray N, Henningford J, Seffrin J, Zatonski W. Oxford University Press; 2004:235-252.

3. Jaworski JN, Linke D, Przewozniak K, Zatonski W: Profilaktyka chorób odtytoniowych - narodowe kampanie zdrowotne. (Prophylaxis of tobacco related diseases - national health campaignes). In Palenie tytoniu w Polsce: postawy, następstwa zrowotne i profilaktyka. (Tobacco smoking in Poland: attitudes, consequences for health, and prophylaxis) Edited by: Zatonski W, Przewozniak K. Warszawa: Centre of Oncology - Institute; 1999:28I-294.

4. Zatonski WA, Willet W: Changes in dietary fat and declining coronary heart disease in Poland: population based study. BM] 2005, 33 I: $187-8$.

5. Zatonski W, Przewozniak K: Cel operacyjny nr 3: Zmniejszenie częstości palenia tytoniu (Operative goal No. 3: A decrease in the prevalence of tobacco smoking). In Kontrola spodziewanych efektów realizacji Narodowego Programu Zdrowia (Control of expected effects of the National Health Program fruition) Edited by: Warszawa: PZH. Gorynski P, Wojtyniak B, Kuszewski K; 2004:49-58.

6. Headquarters of Penitentiary Service: Podstawowe problemy więziennictwa (Fundamental problems of penology). Przegląd Więziennictwa Polskiego 2004, 38-39: I84-190.

7. Central Statistical Office: Rocznik statystyczny Polski (Statistical yearbook of the Republic of Poland) Warszawa; 2004.

8. Cropsey K, Eldridge GD, Ladner T: Smoking among female prisoners: an ignored public health epidemic. Addict Behav 2004, 29:425-31.

9. Young M, Waters B, Falconer T, O'Rourke P: Opportunities for health promotion in the Queensland women's prison system. Aust N Z J Public Health 2005, 29:324-7.

10. Durrah TL: Correlates of daily smoking among female arrestees in New York City and Los Angeles, 1997. Am J Public Health 2005, 95: I788-92.

II. D'Souza RM, Butler T, Petrovsky N: Assessment of cardiovascular disease risk factors and diabetes mellitus in Australian prisons: is the prisoner population unhealthier than the rest of the Australian population? Aust N Z J Public Health 2005, 29:318-23.

12. Centers for Disease Control (CDC): Cigarette smoking bans in county jails-Wisconsin, 1991. MMWR Morb Mortal Wkly Rep 1992, 41: I0I-3.

13. Awofeso N: Reducing smoking prevalence in Australian prisons: a review of policy options. Appl Health Econ Health Policy 2002, I:2 I I-8. 
14. World Health Organization: Guidelines for controlling and monitoring the tobacco epidemic Geneva: WHO; 1998.

I5. Droomers M, Schrijvers CT, Mackenbach IP: Why do lower educated people continue smoking? Explanation from the longitudinal GLOBE study. Health Psychol 2002, 2 I:263-72.

16. Shohaimi S, Luben R, Wareham N, Day N, Bingham S, Welch A, Oakes S, Khaw KT: Residential area deprivation predicts smoking habits independently of individual educational level and occupational social class. A cross sectional study in the Norfolk cohort of the European Investigation into Cancer (EPICNorfolk). J Epidemiol Community Health 2003, 57:270-276.

17. Fagerstrom KO: Measuring degree of physical dependence to tobacco smoking with reference to individualization of treatment. Addict Behav 1978, 3:235-24I.

18. Howard MO, Kivlahan D, Walker RD: Cloninger's tridimensional theory of personality and psychopathology: applications to substance use disorders. J Stud Alcohol 1997, 58:48-66.

19. Shiffman SM: Relapse following smoking cessation: A situational analysis. J Consult Clin Psychol 1982, 50:71-86.

20. Kohn CS, Tsoh IY, Weisner CM: Changes in smoking status among substance abusers: baseline characteristic and abstinence from alcohol and drugs at I2-month follow-up. Drug Alcohol Depend 2003, 69:6I-7I.

21. Cropsey KL, Kristeller JL: Motivational factors related to quitting smoking among prisoners during a smoking ban. Addict Behav 2003, 28:1081-93.

22. Carmody TP: Nicotine dependence: Psychological approaches to the prevention of smoking relapse. Psychol Addict Behav 1993, 7:96-102.

23. Cummings SR, Rubin SM, Oster G: The cost-effectiveness of counselling smokers to quit. I A M A 1989, 26I:75-9.

24. Cohen S, Lichtenstein E, Prochaska JO, Rossi JS, Gritz ER, Carr CR, Orleans CT, Schoenbach VJ, Biener L, Abrams D, DiClemente C, Curry S, Marlatt GA, Cummings KM, Emont SL, Giovino G, OssipKlein D: Debunking myths about self-quitting: Evidence from 10 prospective studies of persons who attempt to quit smoking by themselves. Am Psychol 1989, 44:1355-I365.

25. Curry SJ, Wagner EH, Grothaus LC: Evaluation of intrinsic and extrinsic motivation interventions with a self-help smoking cessation program. J Consult Clin Psychol I991, 59:3 I8-324.

26. Dobrzyniecki J: Kultura fizyczna i resocjalizacja więźniów (Physical culture and resocialization of prisoners) Gdansk: Physical Culture Academic Press; 1998.

27. Rajzner A: Kultura fizyczna w polskim systemie penitencjarnym (Physical culture in the Polish penitentiary system) Warsaw: University of Warsaw Press; 1996.

28. Puisis M: Update on public health in correctional facilities. West J Med 1998, 169:374.

\section{Pre-publication history}

The pre-publication history for this paper can be accessed here:

http://www.biomedcentral.com/1471-2458/6/181/pre pub

\section{Publish with Biomed Central and every scientist can read your work free of charge}

"BioMed Central will be the most significant development for disseminating the results of biomedical research in our lifetime. "

Sir Paul Nurse, Cancer Research UK

Your research papers will be:

- available free of charge to the entire biomedical community

- peer reviewed and published immediately upon acceptance

- cited in PubMed and archived on PubMed Central

- yours - you keep the copyright
BioMedcentral 